\title{
Ambulatory monitoring unmasks hypertension among kidney transplant patients: single center experience and review of the literature
}

\author{
Eitan Gluskin, Keren Tzukert, Irit Mor-Yosef Levi, Olga Gotsman, Itamar Sagiv, Roy Abel, Aharon Bloch, \\ Dvorah Rubinger, Michal Aharon, Michal Dranitzki Elhalel and Iddo Z. Ben-Dov* (i)
}

\begin{abstract}
Background: Disagreements between clinic and ambulatory blood pressure (BP) measurements are well-described in the general population. Though hypertension is frequent in renal transplant recipients, only a few studies address the clinic-ambulatory discordance in this population. We aimed to describe the difference between clinic and ambulatory BP in kidney transplant patients at our institution.

Methods: We compared the clinic and ambulatory BP of 76 adult recipients of a kidney allograft followed at our transplant center and investigated the difference between these methods, considering confounding by demographic and clinical variables.

Results: Clinic systolic BP (SBP) and diastolic BP (DBP) were 128 $\pm 13 / 79 \pm 9 \mathrm{mmHg}$. Awake SBP and DBP were $147 \pm$ $18 / 85 \pm 10 \mathrm{mmHg}$. The clinic-minus-awake SBP and DBP differences were -18 and $-6 \mathrm{mmHg}$, respectively. The negative clinic-awake $\triangle$ SBP was more pronounced at age $>60$ years $(p=0.026)$ and with tacrolimus use compared to cyclosporine $(p=0.046)$. Sleep SBP and DBP were 139 $\pm 21 / 78 \pm 11 \mathrm{mmHg}$. A non-dipping sleep BP pattern was noted in $73 \%$ of patients and was associated with tacrolimus use $(p=0.020)$.
\end{abstract}

Conclusions: Our findings suggest pervasive underestimation of BP when measured in the kidney transplant clinic, emphasizes the high frequency of a non-dipping pattern in this population and calls for liberal use of ambulatory BP monitoring to detect and manage hypertension.

Keywords: Ambulatory blood pressure monitoring, Kidney transplantation, calcineurin inhibitors, cyclosporine, tacrolimus, Masked hypertension, Non-dipping

\section{Background}

Hypertension in renal transplant recipients

In kidney transplant recipients, hypertension (HTN) is an independent risk factor for cardiovascular diseases (CVD) [1, 2], death [3] and graft malfunction independent of death [3-7], and its prevalence is $50-90 \%$ [2, 8, 9]. However, there are no randomized control trials to define target BP levels in renal transplant recipients [10]. The Kidney Disease Improving Global Outcomes (KDIGO) [11] and the American College of Cardiology

\footnotetext{
* Correspondence: iddo@hadassah.org.il

Department of Nephrology and Hypertension, Hadassah - Hebrew University Medical Center, Jerusalem, Israel
}

(ACC) and American Heart Association (AHA) [12] recommendations are to target clinic BP of kidney transplant recipients to levels lower than $130 / 80 \mathrm{mmHg}$ (a $2 \mathrm{C}$-grade recommendation according to KDIGO). Yet, the recommendations of the National Kidney Foundation are to adjust individually BP levels due to lack in evidence based recommendations [13], while the recent European Society of Hypertension (ESH) and the European Society of Cardiology (ESC) guidelines [14] suggest that the target $\mathrm{BP}$ range for patients with chronic kidney disease (CKD) should be $130-139 \mathrm{mmHg}$, and the Eighth Joint National Committee (JNC 8) recommended

(c) The Author(s). 2019 Open Access This article is distributed under the terms of the Creative Commons Attribution 4.0 International License (http://creativecommons.org/licenses/by/4.0/), which permits unrestricted use, distribution, and 
values of less than $140 / 90 \mathrm{mmHg}$ in all CKD patients, not excluding transplant recipients [15].

\section{ABPM and kidney transplantation}

In the general population, clinic BP measurement often differs from ambulatory BP monitoring (ABPM) [16]. Ambulatory BP is monitored at the patient's ordinary environment, and the measurements are recorded every 20-30 min during a period of $24 \mathrm{~h}$ and capture sleep. Hence, ABPM is considered a more reliable measure of BP [17]. Importantly, in the general population ABPM correlates better than clinic BP with end organ damage and cardiovascular outcomes [18-20].

In addition to measuring mean $\mathrm{BP}, \mathrm{ABPM}$ reveals important data on other values, including awake period BP, asleep period BP, BP variability, morning surge and the sleep-related dipping pattern [21]. Furthermore, it can frame differences between clinic BP measurements and home BP monitoring, by establishing masked hypertension and white-coat hypertension [21, 22]. While white coat hypertension leads to overtreatment [23], masked hypertension represents under-diagnosis and therefore under-treatment [24]. Hence, there is a need in parameters in the daily clinical practice that will help in identifying patients with masked hypertension or a prominent masking effect [25].

Only a few studies have examined the concordance between clinic BP and ABPM in kidney transplant recipients. Though some found a high rate of white-coat hypertension [26-29], others found higher rates of masked hypertension [30-32] in this population. Differences in hypertension definitions can account for some of the discrepancy between the studies. Significantly, ABPM better predicts renal graft function [7].

A non-dipping BP pattern (defined as a $<10 \%$ reduction in asleep period BP relative to awake period BP) was reported in up to $79 \%$ of the patients with kidney allografts $[7,28,29]$. In the general population, a nondipping pattern is associated with more complications, including higher rates of stroke, dementia, left ventricular hypertrophy, microalbuminuria and increased carotid intima-media thickening $[9,33]$. In kidney transplantation, a non-dipping pattern links with poor allograft function and high Doppler resistive index [34].

The lack of well-established data with regards to diagnosis, treatment and monitoring of hypertension in the renal transplant population gave rise to a contemporary "Call to Action" published by several European scientific societies, encouraging performance of surveys aimed at assessing the prevalence of hypertension (including white-coat and masked hypertension) [35]. Accordingly, in this study, our objectives were to describe clinic and ambulatory BP, dipping patterns and clinic-awake differences in kidney transplant patients and identify associated clinical parameters.

\section{Methods}

\section{Study population}

We enrolled patients post kidney transplantation followed -up in our renal transplant clinic. Inclusion criteria were age 18 years and above and a period of at least 3 months from the transplantation. Pregnant women were not included. Renal transplant physicians recruited potential participants during regular clinic visits. The Helsinki Committee of the Hadassah Medical Organization approved the protocol for this study. All volunteers provided written informed consent prior to participation.

\section{Data collection}

We collected baseline data including age, weight, transplantation details, underlying kidney disease, medications and BP measurements from medical files, and height and missing information directly from the patients. We calculated the aggregate dose of antihypertensive medications as the sum of percentages of each drug's dose from its maximal dose. We quantified urinary protein excretion and creatinine clearance from a 24-h urine collected during a period before or after the monitoring (up to 3 months for creatinine clearance; for urinary protein, we used data from up to 4 months for renal transplant recipients who were transplanted more than 1 year before the monitoring and 2 months for recipients who were transplanted up to 1 year before the monitoring). Hemoglobin and serum creatinine were measured in the day of monitoring in most patients; in 10 patients, they were measured up to 1 month before or after the monitoring. In a single patient, we collected data from a visit that occurred 4 months before the ABPM. We estimated glomerular filtration rate (eGFR) using the Chronic Kidney Disease Epidemiology Collaboration (CKD-EPI) equation. Trough levels of tacrolimus, everolimus, sirolimus and cyclosporine were measured in the morning of monitoring, before taking the morning dose. In five patients, plasma levels were measured within 8 days after the monitoring; in ten patients, they were measured up to 14 days before the monitoring; in a single patient it was measured 4 months before the monitoring, and in two patients, plasma levels are missing. We make use of information from our institution's ABPM dataset of referred patients for perspective and comparison with this study's patients (registry control) [36]. This registry includes patients ( $47 \%$ women) referred predominantly by the primary physicians for accepted clinical indications. Three percent had diabetes and $65 \%$ had hypertension (as defined by their ambulatory awake BP).

\section{Clinic BP measurements}

$\mathrm{BP}$ was measured either by a nurse (observed) using an oscillometric device (Welch Allyn, 52000 series) before entering the physician's office $(n=16)$, or by the physician, using aneroid auscultatory sphygmomanometry (Accucare 
BP wall mount sphygmomanometer), at least $5 \mathrm{~min}$ after arrival at the clinic $(n=60)$. Typically, single measurements were performed. Our study protocol did not address the particulars of clinic measurements, as our aim was to compare real-life clinic measurements with standardized ambulatory monitoring. Measurements were done on an arm without an arterio-venous fistula, while it rested on a table. Clinic BP was calculated as an average of 2-3 visits during the 3 months before conducting ABPM. If only one measurement was performed in this period, an additional measurement taken 3-12 months before the ABPM was included in the average clinic BP. Hypertension medications were in general not changed during this period. However, adherence and as needed use were not systematically assessed.

\section{Ambulatory blood pressure monitoring}

Ambulatory BP was monitored with Oscar2 devices (SunTech Medical). Three adult cuff sizes were available. Measurements were recorded every $20 \mathrm{~min}$ during the day and every 30 min during nighttime sleep (according to the participant's projection) over a 24-h monitoring period. In the ABPM analysis, awake period limits and asleep period limits were further defined according to the participant's log. Participants with at least 20 awake period measurements and 8 sleep measurements were considered to have a valid $A B P M$ recording. One participant discontinued the monitoring before sleep; his 20 awake period records were included in the study. ABPMs were processed with AccuWin Pro v3 (SunTech Medical).

\section{Outcome definitions}

Clinic HTN was defined as mean clinic SBP $\geq 140$ $\mathrm{mmHg}$ and/or mean clinic $\mathrm{DBP} \geq 90 \mathrm{mmHg}$, according to JNC 8 report [15]. Awake period HTN (ABPM) was defined as mean $\mathrm{SBP} \geq 135 \mathrm{mmHg}$ and/or mean $\mathrm{DBP} \geq$ $85 \mathrm{mmHg}$; asleep period HTN was defined as SBP $\geq 120$ $\mathrm{mmHg}$ and/or DBP $\geq 70 \mathrm{mmHg}$; and $24 \mathrm{~h}$ HTN was defined as $\mathrm{SBP} \geq 130 \mathrm{mmHg}$ and/or $\mathrm{DBP} \geq 80 \mathrm{mmHg}$, according to the ESC recommendations [37].

The primary outcomes of this study were the differences between clinic SBP/DBP and ambulatory awake period SBP/DBP. The secondary outcomes were prevalence of clinic HTN, awake period ambulatory HTN, asleep period ambulatory HTN; white-coat HTN (defined as clinic HTN without awake period ambulatory HTN); masked HTN (defined as awake period ambulatory HTN without clinic HTN); isolated nocturnal HTN; non-dipping pattern (defined as $<10 \%$ reduction in SBP from awake period to sleep time) and a reverse-dipping pattern (defined as higher sleep SBP than awake SBP); as well as assessment of awake and sleep periods' SBP and DBP variability (standard deviation, SD), and average awake period and sleep period heart rates.
Table 1 Characteristics of 76 study participants

\begin{tabular}{|c|c|}
\hline Characteristic & Value \\
\hline Age, years & $52 \pm 14$ \\
\hline $\mathrm{BMI}, \mathrm{kg} / \mathrm{m}^{2}$ & $26.8 \pm 5.2$ \\
\hline Diabetes & $26 \%$ \\
\hline Smoking, never/former/current & $83 \% / 12 \% / 5 \%$ \\
\hline Type of allograft, alive & $74 \%$ \\
\hline Time since transplantation, years & 9.4 (IQR 4.0-16.0) \\
\hline eGFR (CKD-EPI), $\mathrm{ml} / \mathrm{min} / 1.73 \mathrm{~m}^{2}$ & 62.2 (IQR 40.7-75.6) \\
\hline Creatinine clearance, $\mathrm{ml} / \mathrm{min}$ & 61.7 (IQR 42.6-89.0) \\
\hline Urine protein excretion, mg/d & $210($ IQR 140-518) \\
\hline Hemoglobin, g/dl & 13.1 (IQR 11.8-14.3) \\
\hline Anti-hypertensive medications (any) & $74 \%$ \\
\hline ACEi or ARBs & $50 \%$ \\
\hline Beta blockers & $42 \%$ \\
\hline Calcium channel blockers & $39 \%$ \\
\hline Diuretics & $17 \%$ \\
\hline Alpha blockers & $11 \%$ \\
\hline Other anti-hypertensives & $1 \%$ \\
\hline No. of antihypertensive medications & 1 (IQR 0-2) \\
\hline Aspirin & $26 \%$ \\
\hline Statins & $42 \%$ \\
\hline
\end{tabular}

Abbreviations: BMI Body mass index, eGFR Estimated glomerular filtration rate, CKD-EPI Chronic Kidney Disease Epidemiology Collaboration, $A C E i$ Angiotensin converting enzyme inhibitor, ARBs Angiotensin receptor blocker, IQR 1st-3rd quartiles

\section{Statistical analyses}

Sample size calculation for our study was driven by the main hypothesis, that in kidney transplantation, clinically meaningful differences exist between office and ambulatory blood pressure. We estimated that roughly 80 patients are required to detect such differences with 80 $85 \%$ power. Patients' characteristics are summarized as percentages, means and standard deviations or medians and 1st-3rd quartile values, as appropriate. 95\% confidence intervals $(\mathrm{CI})$ for the means of clinic-awake BP differences were calculated using quantile of $\mathrm{t}$ -

Table 2 Immunosuppressive medication usage among study participants

\begin{tabular}{llll}
\hline Medication & Proportion & Daily dose, mg & Levels, ng/ml \\
\hline Prednisone & $93 \%$ & $5(5-5)$ & \\
Mycophenolate & $78 \%$ & $1000(625-1500)$ & \\
Azathioprine & $17 \%$ & $50(50-75)$ & \\
Cyclosporine & $18 \%$ & $150(100-150)$ & $61(48-89)$ \\
Tacrolimus & $72 \%$ & $3.0(2.0-4.25)$ & $7.0(5.5-8.8)$ \\
Everolimus & $5 \%$ & $2.0(1.875-3.0)$ & $4.2(3.4-5.2)$ \\
Sirolimus & $1 \%$ (single pt.) & 1.6 & 7.0 \\
\hline
\end{tabular}

Dosage and levels are expressed as median (1st-3rd quartiles) 
Table 3 Summary of clinic and ambulatory BP monitoring measurements

\begin{tabular}{llll}
\hline Variable & Systolic BP & Diastolic BP & Heart rate \\
\hline Clinic measurements & $128 \pm 13$ & $79 \pm 9$ & $\mathrm{n} / \mathrm{a}$ \\
24h period, $\mathrm{mmHg}$ or bpm & $145 \pm 18$ & $83 \pm 10$ & $\mathrm{n} / \mathrm{a}$ \\
Awake period, mmHg or bpm & $147 \pm 18$ & $85 \pm 10$ & $78 \pm 12$ \\
Sleep period, $\mathrm{mmHg}$ or bpm & $139 \pm 21$ & $78 \pm 11$ & $67 \pm 10$ \\
Sleep-related dip, \% & $5.7 \pm 8.0$ & $8.7 \pm 9.2$ & $12.5 \pm 8.6$ \\
Awake period SD, mmHg & $15 \pm 4$ & $10 \pm 3$ & $\mathrm{n} / \mathrm{a}$ \\
Asleep period SD, mmHg & $13 \pm 5$ & $10 \pm 4$ & $\mathrm{n} / \mathrm{a}$ \\
\hline
\end{tabular}

Abbreviations: BP Blood pressure, SD Standard deviation, BP Blood pressure, n/a Not available

distribution ( $\mathrm{R}$ package 'Publish'). We evaluated associations between clinic and ambulatory BP means or indices (e.g. dipping, variability) and demographic and clinical characteristics with general linear (and logistic) regression models using the $\mathrm{R}$ statistical environment (and packages including 'Rmisc' and 'nlme'). Proteinuria $(\mathrm{mg} / \mathrm{d})$ was log-transformed prior to inclusion in models. Plots were generated using $\mathrm{R}$ base functions and the 'ggplot2', 'BlandAltmanLeh' and 'waffle' packages. Two-tailed $P$-values $<0.05$ were considered statistically significant. P-value adjustment for multiple comparisons and post-hoc analyses was done by the Benjamini \& Hochberg method.

\section{Results}

Between 12/2016 and 2/2018 seventy-six subjects were recruited to the study. Their demographic, anthropometric and clinical characteristics appear in Table 1. Immunosuppressive medication treatment data are displayed in Table 2.

$\mathrm{BP}$ average across the $2-3$ most recent clinic visits was $128 \pm 13 / 79 \pm 9 \mathrm{mmHg}$, Table 3. Associations of BP levels with clinical variables are depicted in Table 4 and further described in Additional file 1. Categorically, presence of clinic HTN (SBP $\geq 140 \mathrm{mmHg}$ and/or DBP $\geq 90 \mathrm{mmHg}$ ), was noted in $16 / 56(29 \%)$ of patients treated with antihypertensive medications and in 5/20 (25\%) of untreated patients (all 5 also had ambulatory HTN) (see Table 4 and Additional file 1).

Awake, sleep and $24 \mathrm{~h} \mathrm{BP}$ as well as sleep-related dipping averages are displayed in Table 3 . Links with clinical parameters are depicted in Table 4 and in Additional files 1 and 2. Presence of awake HTN (average $\mathrm{SBP} \geq 135 \mathrm{mmHg}$ and/or average $\mathrm{DBP} \geq 85 \mathrm{mmHg}$ ) was noted in $43 / 56$ (77\%) of patients treated with antihypertensive medications and in 16/20 (80\%) of untreated patients. Sleep HTN (average SBP $\geq 120 \mathrm{mmHg}$ and/or average DBP $\geq 70 \mathrm{mmHg}$ ) was noted in $48 / 55$ (87\%) of patients treated with antihypertensive medications and in $16 / 20(80 \%)$ of untreated patients.

Isolated nocturnal HTN was present in $11 \%$ of participants. Rates of normal systolic BP dipping pattern, non-

Table 4 Associations of clinic and ambulatory BP parameters with clinical variables

\begin{tabular}{|c|c|c|c|c|c|c|c|c|}
\hline BP variable $\rightarrow$ & Clinic & Clinic & Awake & Sleep & Sleep dip & Sleep & Non-dip & Awake SD \\
\hline Clinical variable $\downarrow$ & SBP/DBP & HTN & SBP/DBP & SBP/DBP & SBP/DBP & HTN & SBP/DBP & $\mathrm{SBP} / \mathrm{DBP}$ \\
\hline Age $>60 y$ & $\mathrm{NS} /-4.6^{\mathrm{a}}$ & - & $+10.0^{\mathrm{a}} / \mathrm{NS}$ & - & - & - & - & $+3.1^{\mathrm{b}} / \mathrm{NS}$ \\
\hline Sex, male & - & - & - & - & - & - & - & - \\
\hline $\mathrm{BMI}, \mathrm{kg} / \mathrm{m}^{2}$ & $+0.82^{\mathrm{b}} / \mathrm{NS}$ & - & - & - & - & - & - & - \\
\hline Diabetes & $+7.9^{\mathrm{a}} / \mathrm{NS}$ & - & $N S /-6.3^{a}$ & $+11.3^{\mathrm{a}} / \mathrm{NS}$ & $\mathrm{NS} /-0.07^{\mathrm{b}}$ & - & - & $+2.4^{\mathrm{a}} / \mathrm{NS}$ \\
\hline Cadaveric allograft & - & - & $N S /-6.3^{a}$ & - & - & - & - & - \\
\hline Time since $T x, y$ & - & - & - & - & - & $-0.10^{\mathrm{a}}$ & - & - \\
\hline Proteinuria, $\log _{10}(\mathrm{mg} / \mathrm{d})$ & $+9.8 \mathrm{~b} / \mathrm{NS}$ & $+1.8^{\mathrm{b}}$ & $+10.0^{\mathrm{a}} / \mathrm{NS}$ & - & - & - & - & - \\
\hline HTN medications, \# & $+3.1^{\mathrm{c}} / \mathrm{NS}$ & - & $+3.4^{\mathrm{a}} / \mathrm{NS}$ & $+4.0^{\mathrm{a}} / \mathrm{NS}$ & - & - & - & - \\
\hline HTN medications, cumulative dose & $+0.05^{\mathrm{c}} / \mathrm{NS}$ & - & $+0.07^{\mathrm{C}} / \mathrm{NS}$ & $0.07^{\mathrm{b}} / \mathrm{NS}$ & - & - & - & - \\
\hline HTN medications, evening dosing & - & - & - & - & - & - & - & $\mathrm{NS} /-1.2^{\mathrm{a}}$ \\
\hline $\mathrm{eGFR}, \mathrm{ml} / \mathrm{min} / 1.73 \mathrm{~m}^{2}$ & $-0.22^{\mathrm{C}} / \mathrm{NS}$ & $-0.03^{\mathrm{a}}$ & - & - & - & - & - & - \\
\hline $\mathrm{CrCl}, \mathrm{ml} / \mathrm{min}$ & $-0.12^{\mathrm{a}} / \mathrm{NS}$ & $-0.03^{\mathrm{a}}$ & - & - & - & - & - & - \\
\hline P. creatinine, $\mu \mathrm{mol} / \mathrm{I}$ & - & $+0.01^{\mathrm{a}}$ & - & - & - & - & - & - \\
\hline Tacrolimus vs CsA & - & - & - & - & $\mathrm{NS} /-0.08^{\mathrm{b}}$ & $+1.9^{\mathrm{a}}$ & $+1.5^{\mathrm{a}} / \mathrm{NS}$ & - \\
\hline Hemoglobin, g/dl & - & - & - & - & $+0.01^{a} /+0.01^{a}$ & - & - & - \\
\hline
\end{tabular}

Cell values represent the coefficient ( $($ ) in a model with the BP-related parameter (column names) as the independent variable and the clinical parameter (row names) as the dependent variable. Abbreviations: BMI Body mass index, eGFR Estimated glomerular filtration rate, $\mathrm{CrCl} C \mathrm{Creatinine}$ clearance, $\mathrm{CSA} C \mathrm{Cyclosporine}$ SBP Systolic blood pressure, DBP Diastolic blood pressure, HTN Hypertension, SD Standard deviation, NS (as well as '-') Non-significant; ${ }^{a} \mathrm{p}<0.05$ (but not significant after adjustment for multiple comparisons); ${ }^{b} p \leq 0.005$ (in some cases borderline after adjustment for multiple comparisons; ${ }^{c} p \leq 0.001-$ see multiple comparisonadjusted $\mathrm{p}$-values in Additional file 3 
dipping pattern and reverse dipping pattern were $26.7 \%$ (20 patients), 53.3\% (40 patients) and 20\% (15 patients), respectively. In contrast, non-dipping of heart rate $(<10 \%$ reduction during sleep) was noted in only $43 \%$ of subjects.

The discrepancy between ambulatory and clinic BP was expressed as clinic minus awake $\mathrm{SBP}, \triangle \mathrm{SBP}$, and clinic minus awake DBP, $\triangle \mathrm{DBP}$. The distribution of $\triangle \mathrm{SBP}$ $(-18.5,95 \% \mathrm{CI}-22.4$ to $-14.6 \mathrm{mmHg})$ and $\triangle \mathrm{DBP}(-6.4$, $95 \% \mathrm{CI}-8.6$ to $-4.2 \mathrm{mmHg}$ ) values is shown in Fig. 1a, alongside analogous control data from an independent dataset of referred patients [36] for perspective. $\triangle$ SBP and $\triangle \mathrm{DBP}$ are also shown versus the respective average values of awake and clinic BP (Bland-Altman plots, Fig. 1b). The standard deviations (SD) of the differences were 17.1 and $9.7 \mathrm{mmHg}$ respectively, and the $95 \%$ limits of agreement (1.96*SD) were -52.6 to $+15.7 \mathrm{mmHg}$ for SBP and -35.8 to +13.0 for DBP (the limits of agreement show the estimated range within which the differences between single readings by the two modalities would fall on $95 \%$ of occasions) (Fig. 1b). $\triangle \mathrm{SBP}$ was positively dependent on age (mean $\Delta$ SBP for age $>60-24.7,95 \% \mathrm{CI}-32.9$ to -16.5 mmHg; mean $\triangle$ SBP for age $\leq 60-15.4,95 \% \mathrm{CI}-19.6$ to $-11.3 \mathrm{mmHg} ; p=0.026$ ), on the immunosuppressive regimen (mean $\triangle$ SBP for cyclosporine $-9.6,95 \% \mathrm{CI}-17.4$ to
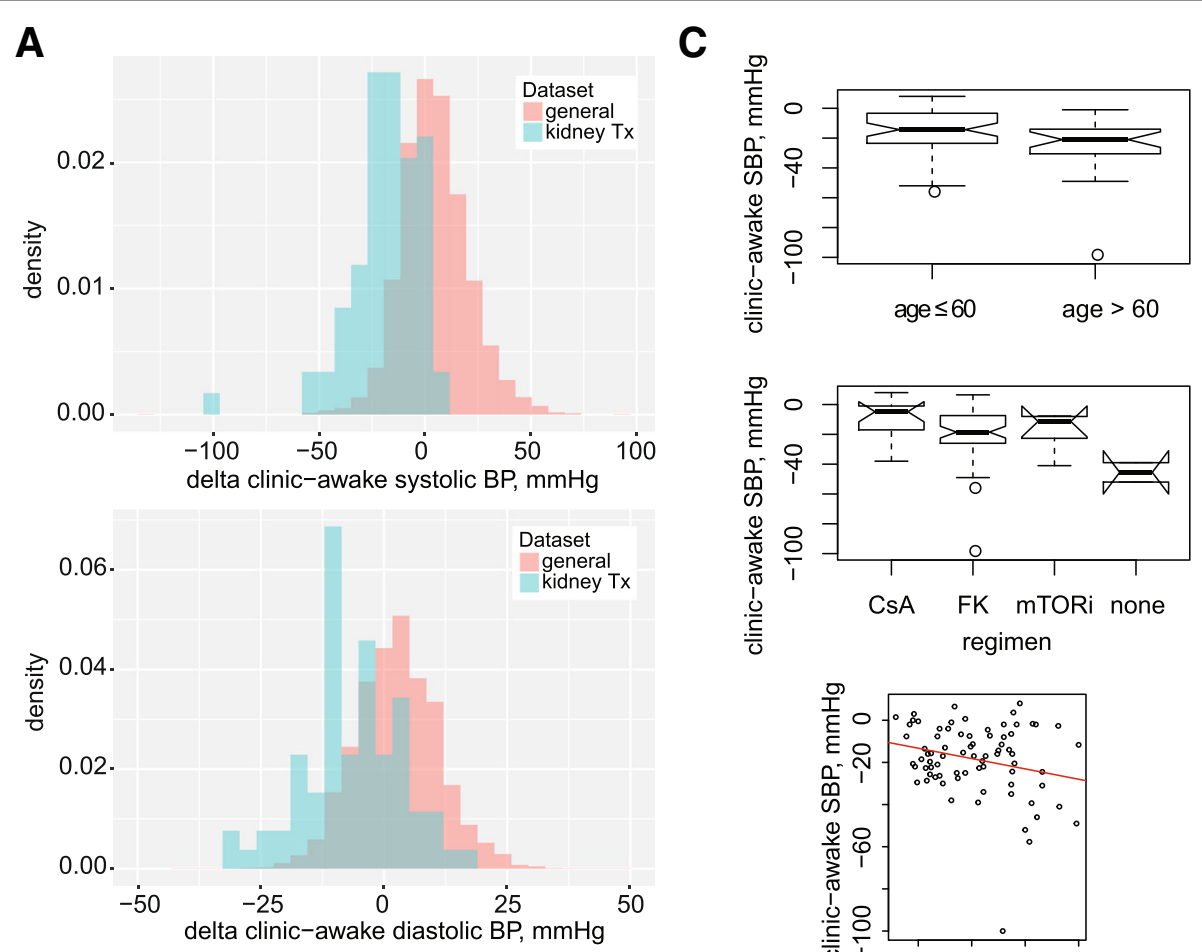

\section{B}
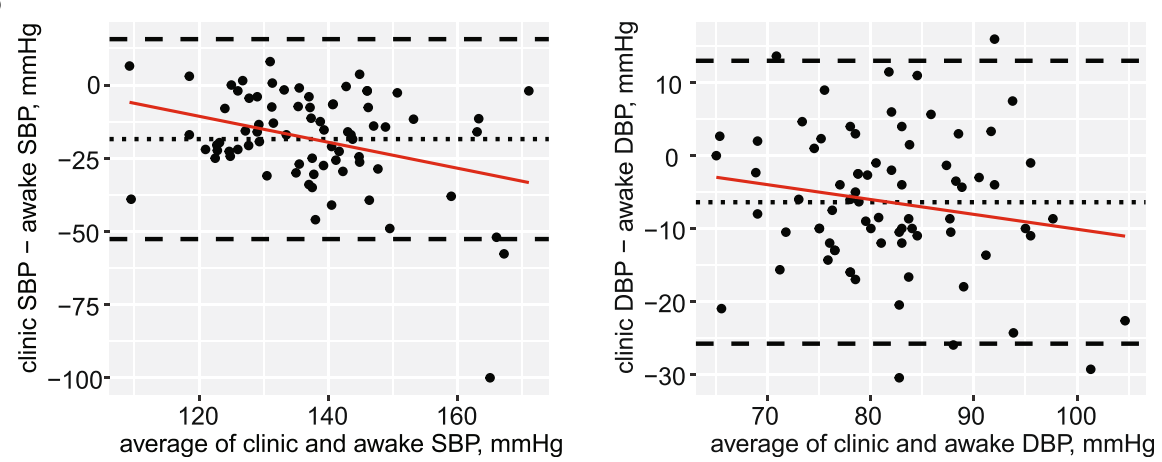

Fig. 1 Distribution and clinical correlates of the clinic-awake BP difference. a Density histograms plotting the distribution of $\triangle B P$ values; clinic-awake systolic BP (top) and diastolic BP (bottom). For reference, the respective distributions are shown from an ABPM referral dataset. $\mathbf{b}$ Bland-Altman plots of $\triangle \mathrm{SBP}$ (left) or $\triangle \mathrm{DBP}$ (right) vs. the respective average of awake and clinic BP. The dotted line represents the mean difference while the dashed lines represent the $95 \%$ limits of agreement ( \pm 2 standard deviations of the difference) (c) Dependence of $\Delta$ SBP on age (top), immuno-suppressive regimen (middle) and the variability of awake SBP (bottom) 
- $1.9 \mathrm{mmHg}$; mean $\triangle \mathrm{SBP}$ for tacrolimus use - 19.8, 95\% $\mathrm{CI}-24.4$ to $-15.1 \mathrm{mmHg}$; mean $\triangle \mathrm{SBP}$ for no calcineurin inhibitor use $-26.0,95 \% \mathrm{CI}-42.7$ to $-9.3 \mathrm{mmHg} ; p=$ $0.025)$ and on the variability of awake systolic BP ( $p=$ 0.034) (Fig. 1c and Table 5). After adjustment for age $>60$, the association of $\triangle \mathrm{SBP}$ with the immunosuppressive regimen dampened $(p=0.094)$, as did the dependence on age as a continuous variable $(p=0.064)$. The association of $\triangle \mathrm{SBP}$ with the immunosuppressive regimen did not lose significance after adjustment for time since transplantation $(p=0.048)$ or for diabetes $(p=0.046)$.

Figure 2a shows clinic and ambulatory awake systolic $\mathrm{BP}$ values, in an overlapping manner, according the immunosuppressive regimen. The discrepancy appears wider among patients receiving tacrolimus. However, neither clinic (Fig. 2b) nor awake (Fig. 2c) systolic BP averages were dependent on trough drug levels among patients receiving tacrolimus.
To further characterize diurnal BP patterns in relation to calcineurin inhibitor use we extracted individual patients' BP measurements from all ABPM tracings. Hourly averages as well as $3 \mathrm{~h}$ interval averages are plotted according to calcineurin inhibitor use in Fig. 3. SBP was significantly higher among tacrolimus users in the 16:00-04:00 time intervals; DBP was higher throughout the 22:00-07:00 time intervals; and heart rate was significantly lower among tacrolimus users in the 16:00-19:00 time interval. According to a linear mixed effects model, the diurnal time interval was a significant predictor of SBP, DBP and heart rate (all $p$-values $<0.0001$ ), while the interaction between medication and time interval predicted $\operatorname{SBP}(p=0.061)$ and $\operatorname{DBP}(p=$ $0.013)$.

According to JNC8 definitions for clinic HTN and to ESC-ESH recommendations for ambulatory HTN, rates of white coat HTN, masked HTN, sustained HTN and

Table 5 Associations of the clinic-awake BP differences $(\triangle B P)$ with clinical variables

\begin{tabular}{|c|c|c|c|c|}
\hline \multirow[t]{2}{*}{ Parameter } & \multicolumn{2}{|l|}{$\triangle \mathrm{SBP}$} & \multicolumn{2}{|l|}{$\triangle \mathrm{DBP}$} \\
\hline & Coefficient & $P$-value & Coefficient & $P$-value \\
\hline Age $>60$ years & -9.2 & 0.026 & -1.2 & 0.624 \\
\hline BMl, $\mathrm{kg} / \mathrm{m}^{2}$ & 0.3 & 0.402 & -0.1 & 0.722 \\
\hline Diabetes & 0.2 & 0.964 & 3.0 & 0.231 \\
\hline Past smoking vs. never & -0.5 & 0.929 & -4.7 & 0.179 \\
\hline Type of allograft, cadaveric vs. alive & 0.7 & 0.874 & 2.5 & 0.324 \\
\hline Time since transplantation, years & 0.1 & 0.614 & -0.03 & 0.809 \\
\hline eGFR (CKD-EPI), ml/min/1.73m² & -0.1 & 0.171 & 0.01 & 0.855 \\
\hline Creatinine clearance, $\mathrm{ml} / \mathrm{min}$ & -0.1 & 0.302 & 0.02 & 0.525 \\
\hline Urine protein excretion, mg/d $\left(\log _{10}\right)$ & -0.3 & 0.956 & 2.4 & 0.364 \\
\hline Hemoglobin, g/dl & -1.3 & 0.244 & 0.2 & 0.697 \\
\hline Anti-hypertensive medications (any) & 6.1 & 0.173 & 1.6 & 0.532 \\
\hline ACEi or ARBS & 3.4 & 0.393 & -0.2 & 0.915 \\
\hline Beta blockers & 0.8 & 0.847 & 2.1 & 0.358 \\
\hline Calcium channel blockers & -0.2 & 0.968 & 0.2 & 0.947 \\
\hline Diuretics & -3.4 & 0.521 & -2.7 & 0.365 \\
\hline Alpha blockers & -2.3 & 0.727 & 0.9 & 0.815 \\
\hline No. of antihypertensive medications & -0.3 & 0.800 & -0.2 & 0.798 \\
\hline Aspirin & -0.1 & 0.984 & 3.0 & 0.242 \\
\hline Tacrolimus vs. cyclosporine & -10.1 & 0.046 & -1.8 & 0.546 \\
\hline Non-CNI vs. cyclosporine & -16.3 & 0.038 & -3.5 & 0.446 \\
\hline Siesta & 4.7 & 0.441 & 0.5 & 0.892 \\
\hline Oscillometric vs. aneroid clinic measurement & 7.0 & 0.146 & 3.7 & 0.177 \\
\hline Clinic $\mathrm{BP}, \mathrm{mmHg}$ & 0.4 & 0.003 & 0.4 & $<0.001$ \\
\hline SD of awake ambulatory $\mathrm{BP}, \mathrm{mmHg}$ & -1.0 & 0.034 & -0.7 & 0.076 \\
\hline
\end{tabular}

Abbreviations: BMI Body mass index, eGFR Estimated glomerular filtration rate, CKD-EPI Chronic Kidney Disease Epidemiology Collaboration, ACEi Angiotensin converting enzyme inhibitor, $A R B s$ Angiotensin receptor blocker, $C N I$ Calcineurin inhibitor, BP Blood pressure, SD Standard deviation Bold entries are significant 


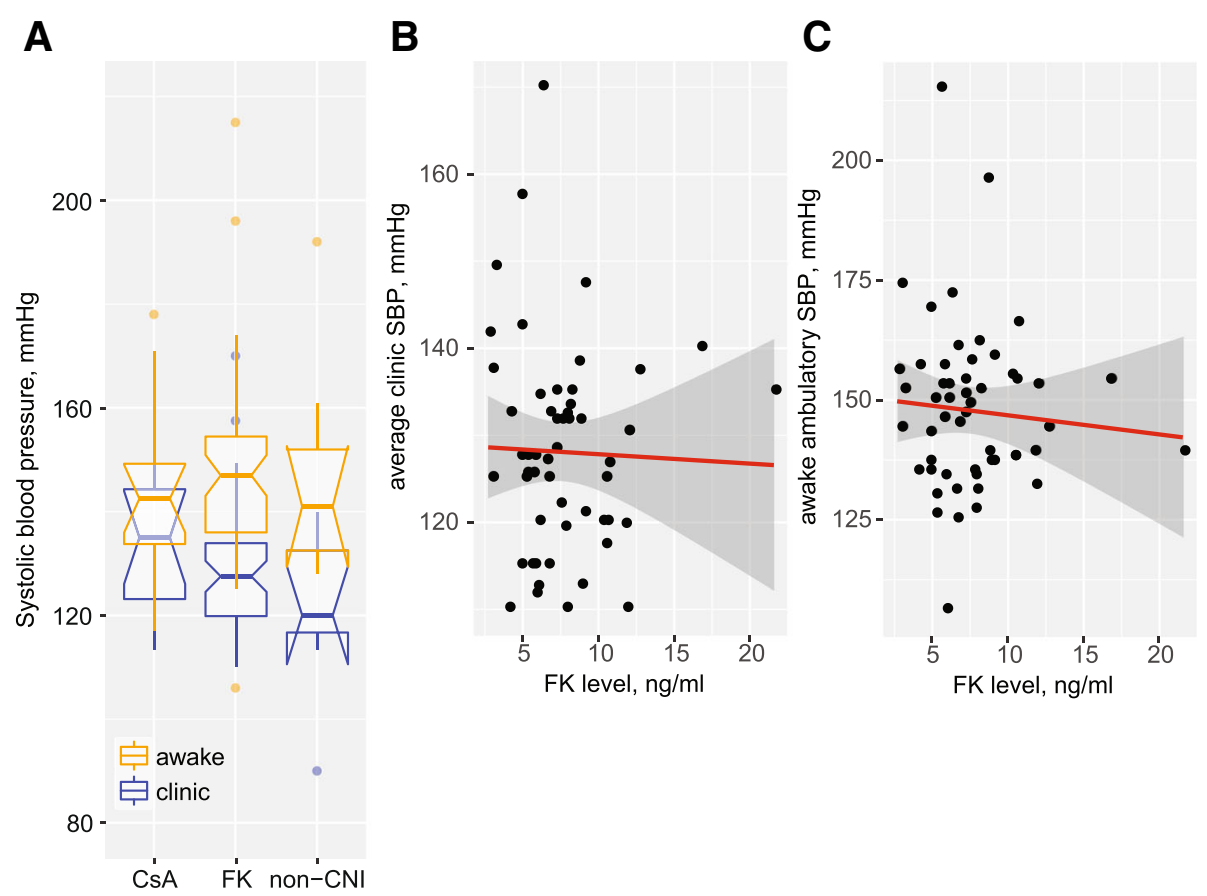

Fig. 2 Clinic and awake systolic BP in relation to tacrolimus use. a Box plots summarizing clinic and awake SBP levels among patients treated with cyclosporine, tacrolimus or neither calcineurin inhibitor. b, c Lack of relationship was noted between clinic SBP (b) or ambulatory awake SBP (c) and tacrolimus trough levels

normotension were $1.3,51.3,26.3,21.1 \%$, respectively (Fig. 4a). However, according to KDIGO and ACC recommendations for clinic BP targets $(<130 / 80 \mathrm{mmHg})$, the respective proportions were $9.2,22.4,55.3$, and 13.2\% (Fig. 4b).

\section{Discussion}

In our study, employing ambulatory blood pressure monitoring, we found that patients followed at our kidney transplant clinic have appreciably higher systolic and diastolic BP levels outside the office as compared to their clinic measurements. The differences, averaging 18 and $6 \mathrm{mmHg}$, respectively, expose widespread underestimation of BP, misclassification of BP control and masked hypertension in our kidney transplantation clinic. The limits of agreement between ambulatory awake and clinic BP measurements were wide (see Fig. 1b).

In our study, the negative clinic-awake SBP difference (i.e., masking) was more pronounced with age over 60 years and with tacrolimus use (versus cyclosporine). In the general population, one study found age to be a risk factor for masked HTN [38]; other studies, however, found that the clinic-awake difference increases (i.e., more positive) with age [25] and thus elderly have more white-coat effect [39]. Tacrolimus use was found in other studies [40, 41] in association with lower clinic BP. We suggest that this association may not be true with regards to ambulatory BP and may thus lead to underestimation (and under- treatment) of BP in tacrolimus-treated patients evaluated using clinic measurements alone. However, we have not pre-specified subset analyses based on age and calcineurin inhibitor regimen, and patients receiving cyclosporine were scarce, and thus results are not conclusive.

As a result of the negative clinic-awake BP difference in our patients, masked HTN was uncovered much more commonly than white coat HTN. This finding is sensitive to clinic HTN definitions. The ACC/AHA and KDIGOadopted lower clinic BP thresholds amplify the prevalence of sustained HTN on account of masked HTN and that of white coat HTN on account of normotension. Overall, $\mathrm{KDIGO/ACC/AHA} \mathrm{guideline} \mathrm{cutoffs} \mathrm{lead} \mathrm{to} \mathrm{more} \mathrm{agree-}$ ment between clinic- and ABPM awake-based determinations than JNC 8 cutoffs (69\% vs. $47 \%$ ).

\section{Review of the literature with regards to $\triangle \mathrm{BP}$ in kidney transplantation}

Previous studies have also shown negative clinicambulatory BP differences in renal transplant populations, albeit of lesser extent. However, in several other studies opposing results have been noted. These previous studies differ one from another in patients' age, clinic BP and ABPM methods and in exclusion criteria (Table 6).

In a study of 98 patients from New-Zealand [30], the mean differences between clinic SBP and DBP and average $24 \mathrm{~h}$ SBP and DBP were $-3.5 \mathrm{mmHg}$ and -7.2 


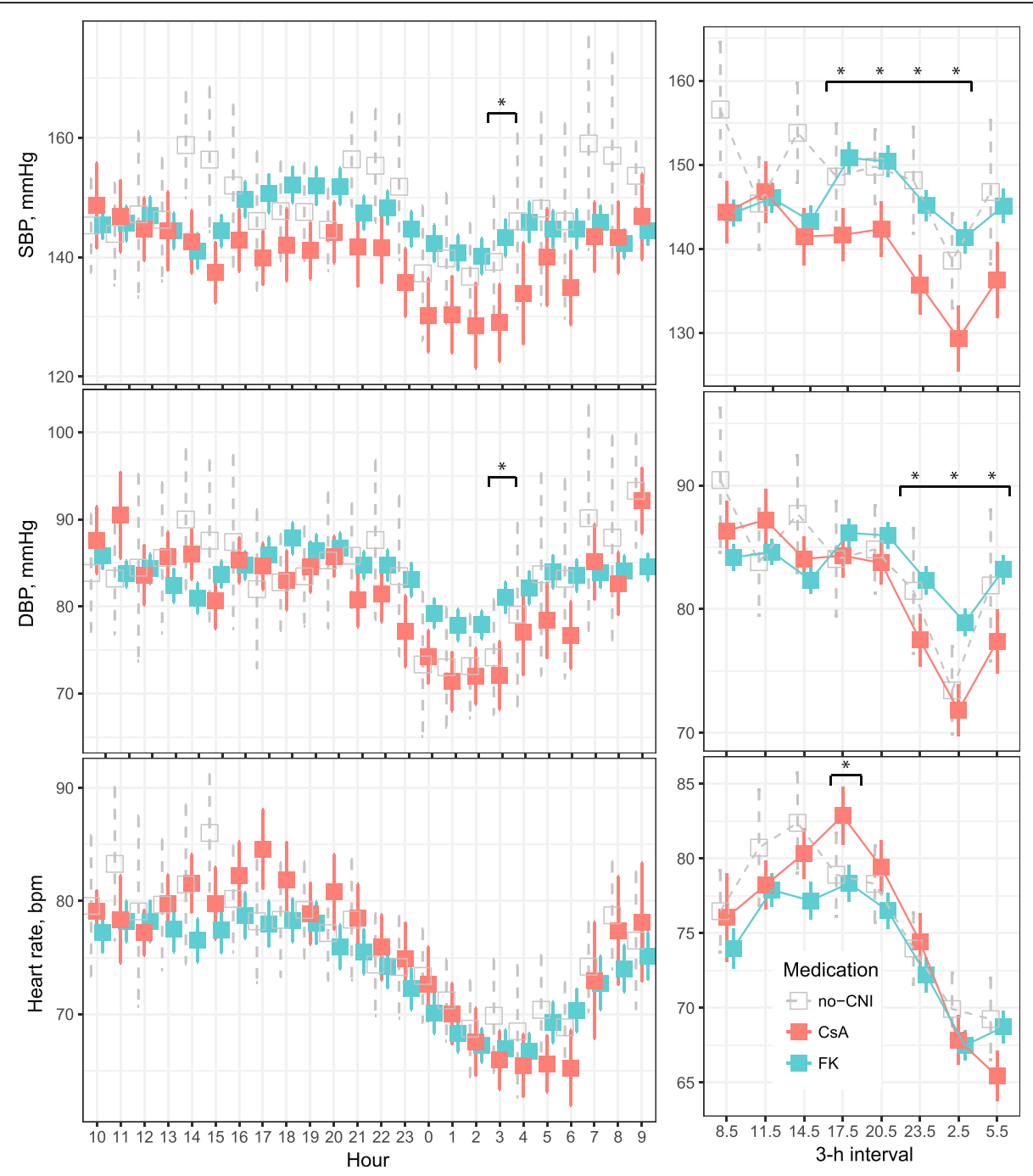

Fig. 3 Diurnal ambulatory monitoring patterns in relation to calcineurin inhibitor use. Hourly averages (left panels) and 3-h interval averages (right panels) of ambulatory systolic BP (top), diastolic BP (middle) and heart rate (bottom) are plotted according to calcineurin inhibitor use, with bars indicating standard error of the mean. Asterisks $\left(^{*}\right)$ denote time points or intervals in which levels were significantly different between tacrolimus and cyclosporine-treated study patients

$\mathrm{mmHg}$, respectively. These values are also negative, but they are less negative than the current study's values. There are several explanations for this difference: (1) In this study, clinic SBP was compared to $24 \mathrm{~h} B \mathrm{BP}$, which was lower than awake BP. (2) The clinic BP was measured as an average of all the measurements in the study period, apparently including measurements that were done after (and may have been affected by) the ABPM. (3) The study was conducted at a research center, with which the patients were not familiar. (4) Patients with unstable BP levels (not defined) were not included. In a 113-patient Turkish study [32], the mean differences between clinic SBP and DBP and average awake SBP and DBP were $-9.0 \mathrm{mmHg}$ and $-6.4 \mathrm{mmHg}$, respectively. Patients with uncontrolled HTN (not defined) were excluded. Lastly, in 172 Italian patients, the clinic - awake
SBP and DBP differences were $-1 \mathrm{mmHg}$ [42]; clinic BP was measured only in the monitoring day.

On the other hand, in a 260-patient Italian study, the clinic - awake SBP and DBP differences were +6 and $0 \mathrm{mmHg}$, respectively [43]. The clinic measurements in the Italian study were done after the ABPM, a fact that could has influenced the results, and the clinic BP was measured as the mean of BP measurements within a mean period of 3.7 years. In another 87-patient Turkish study, the clinic - awake SBP and DBP differences were +6 and $+4.5 \mathrm{mmHg}$, respectively [29]; however, several exclusion criteria have been used in this Turkish study (history of diabetes mellitus, heart failure, ischemic heart disease, cardiomyopathy, or significant valvular heart disease; hemoglobin level $<10 \mathrm{~g} / \mathrm{dL}$; and serum creatinine 


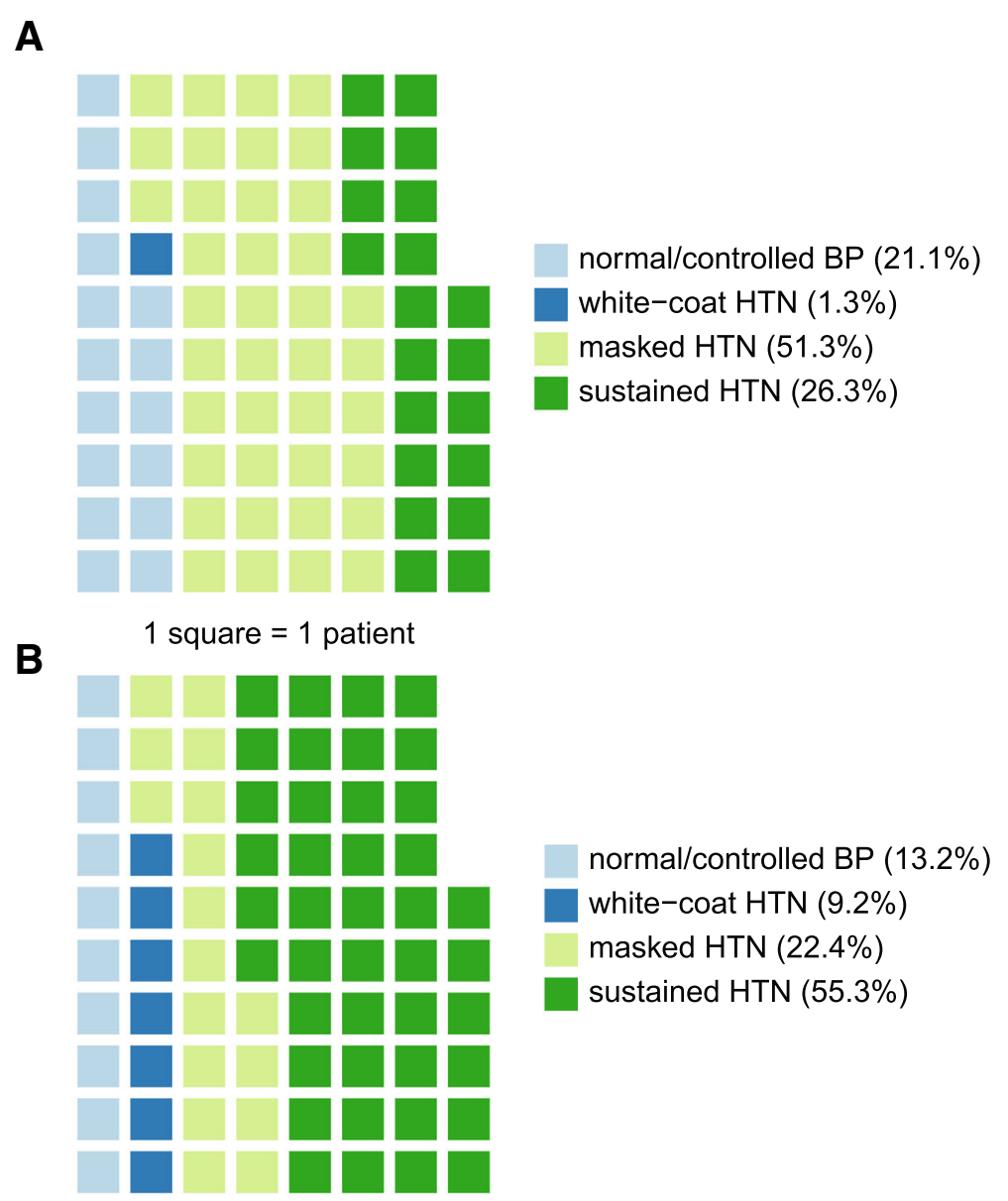

Fig. 4 Rates of clinic vs awake blood pressure patterns. Waffle plots showing the prevalence of blood pressure control patterns among study patients, considering (a) JNC8 clinic hypertension cutoffs, 140/90 mmHg, or (b) KDIGO and ACC-recommended clinic cutoffs, 130/80 mmHg

level $>1.5 \mathrm{mg} / \mathrm{dL})$. Among 244 Canadian patients, the clinic - awake SBP and DBP differences were +3.6 and $+2.5 \mathrm{mmHg}$, respectively [28]. In this Canadian study, one clinic measurement was recorded, obtained within 5 days of ABPM (not mentioned if before or after the ambulatory monitoring). More importantly, the average clinic BP in the Canadian study was $137 / 79 \mathrm{mmHg}$, higher than the value in our study. Higher clinic BP levels are associated with less negative clinic - awake BP differences (Fig. 1b).

In a 49-patient Indian study, the clinic - awake SBP and DBP differences were positive at 2, 4, 6, and 9 months after transplantation [26]; however, the mean age of the participants in the Indian study was 35 years, and the methodology of clinic BP measurement was different (it was calculated as a mean of a clinic measurement, the first ABPM measurement and the last ABPM measurements). In a Spanish multicenter study (868 patients), the clinic - awake SBP and DBP differences were +7 and $+1 \mathrm{mmHg}$, respectively [27]; however, kidney transplant recipients with $\mathrm{Scr}>2.5 \mathrm{mg} / \mathrm{dL}$ or with
eGFR $<30 \mathrm{ml} / \mathrm{min} / 1.73 \mathrm{~m}^{2}$ were not included, and description of clinic and ABPM measurement methodology is lacking. In a 94-patient Italian study, the clinic - awake SBP and DBP differences were +4 and $-1 \mathrm{mmHg}$, respectively [7]. A possible explanation for this difference is that in this Italian study the clinic BP was $150 / 86 \mathrm{mmHg}$ on average, and in our study higher clinic BP measurements associated with less negative delta values, as mentioned previously (Fig. 1b).

As in our study, the tendency for a negative clinicawake BP difference has been observed in other (nontransplant) CKD populations. In an US cross-sectional study on 1492 CKD patients, the differences between clinic and ambulatory awake SBP and DBP were -5.9 and $-6.4 \mathrm{mmHg}$, respectively [44]. In a Japanese study [45], masked HTN was more prevalent than white coat HTN among stage $3-5$ CKD patients.

In addition to the clinic-awake discrepancy, nocturnal measurements have revealed that $83 \%$ of our patients have sleep HTN. This finding is in line with previous results $(69 \%$ [42], $71 \%$ [30]). Also, only $23 \%$ of the 
Table 6 clinic-awake SBP and DBP differences from previous studies

\begin{tabular}{|c|c|c|c|c|c|c|c|c|}
\hline Study & No. & Age & $\triangle \mathrm{SBP}$ & $\triangle \mathrm{DBP}$ & Clinic BP & FK vs. CsA & Exclusion & Other \\
\hline Ahmed 2015 [30] & 98 & 55 & -3.5 & -7.2 & all study measurements & no comparison & unstable BP & new center \\
\hline Kayrak 2014 [32] & 113 & 44 & -9 & -6.4 & & no comparison & $\begin{array}{l}\text { uncontrolled } \\
\text { hypertension }\end{array}$ & \\
\hline Mallamaci 2016 [42] & 172 & 46 & -1 & -1 & monitoring day only & no comparison ${ }^{a}$ & & \\
\hline Mallamaci 2018 [43] & 260 & 47 & +6 & 0 & $\begin{array}{l}\text { after ABPM, mean } 3.7 \\
\text { years }\end{array}$ & no comparison & & \\
\hline Demikrol 2016 [29] & 87 & 38 & +6 & +4.5 & & $\begin{array}{l}\text { no difference in } \\
\text { dipping }\end{array}$ & comorbidities & \\
\hline Wen 2012 [28] & 244 & 53 & +3.6 & +2.5 & $\begin{array}{l}\text { measurement within } 5 \\
\text { days }\end{array}$ & $\begin{array}{l}\text { no effect on ABPM } \\
\text { values }\end{array}$ & & $\begin{array}{l}\text { higher clinic BP } \\
\text { levels }\end{array}$ \\
\hline David 2014 [26] & 49 & 35 & $+3-12$ & $+6-8$ & $\begin{array}{l}\text { clinic and 1st and last } \\
\text { ABPM measurements }\end{array}$ & FK only & & \\
\hline Fresendo 2012 [27] & 868 & 53 & +7 & +1 & absent data & no comparison & & reduced GFR \\
\hline Paoletti 2009 [7] & 94 & 55 & +4 & +1 & & Lower PP with FK & & $\begin{array}{l}\text { higher clinic BP } \\
\text { levels }\end{array}$ \\
\hline
\end{tabular}

Abbreviations: SBP Systolic blood pressure, DBP Diastolic blood pressure, FK Tacrolimus, CSA Cyclosporine, BP Blood pressure, CNI Calcineurin inhibitor, ABPM Ambulatory blood pressure monitoring, DM Diabetes mellitus, HF Heart failure, IHD Ischemic heart disease; CMP Cardiomyopathy, GFR Glomerular filtration rate, $P P$ Pulse pressure

${ }^{\text {a }}$ Sirolimus associated with higher dipping ratio

patients in our study were normal dippers. This too is similar to previous findings (21\% [7], 32\% [29], 14\% [27], 27\% [46]). High rates of non-dipping have also been shown in liver transplant patients, treated with cyclosporine or tacrolimus [47], and in cyclosporine treated heart transplant recipients [48]. In our study, a non-dipping pattern was associated with tacrolimus use, even after adjustment for diabetes, time since transplantation and age. Low hemoglobin levels were linked to lower SBP and DBP dipping ratio; this finding is consistent with data from the general population [49]. As compared with BP dipping, heart rate dipping during sleep, an independent predictor of mortality [50], was relatively preserved in our patients.

In the absence of significant relationships with age, diabetes and BMI, the elevated magnitude of BP masking and non-dipping observed in our patients is possibly a consequence of disturbed volume status, as has been shown for tacrolimus treatment [51], and derangements in autonomic nervous system activity. Also, in as much as anxiety and stress may be involved in the white-coat BP response [52], it is tempting to speculate that for a kidney transplant patient in a routine visit, the kidney transplant clinic constitutes a comforting environment, with familiar fellow patients and more importantly staff, with whom not rarely a patient may have more than a decade long familiarity (being that kidney transplant physicians and nurses also care for dialysis and pre-dialysis patients). Thus, hypertension may be masked in the kidney transplant clinic much more often than a white coat response is elicited.

\section{Limitations}

Recruitment of participants was performed predominantly by their transplant nephrologists, possibly leading to referral biases toward patients who their physicians thought them to have indications for ABPM. Also, clinic BP measurements were not done in a uniform manner: 5 of 7 physicians used aneroid sphygmomanometry, while two relied on oscillometric measurements taken by the clinic nurse. Only one measurement was typically recorded in each visit. Our study has no dedicated control group, although we did use parallel information from our institution's general ABPM dataset for perspective. Our study's relatively small size (76 patients who take different antihypertensive medications) is a limitation too, and caution is advised in interpreting some results also due to their post-hoc nature.

On the other hand, our study's strength is in examining the clinic-awake BP difference as a continuous variable, and therefore independent of hypertension definitions. To our knowledge, it is the first study that describes diurnal-based BP differences between immunosuppressant regimens, thus generating hypothesis for further studies.

\section{Conclusions}

We conclude that ABPM is justified in the renal transplant population. This is due to the high proportion of masked hypertensives and a predominating negative clinic-awake BP difference, and due to the lack of robust predictors of masking. 


\section{Additional files}

Additional file 1: Supporting description and correlation analysis of blood pressure parameters. A Microsoft Word file with supplementary results. (DOCX $32 \mathrm{~kb}$ )

Additional file 2: PDF file containing 4 supplementary figures. (PDF $440 \mathrm{~kb}$ ) Additional file 3: Table S1. Benjamini-Hochberg adjusted $p$-values corresponding to the association matrix presented in Table 4 (values $<0.05$ are highlighted). A Microsoft Excel file containing supplementary results. (XLSX $12 \mathrm{~kb})$

\section{Abbreviations}

ABPM: Ambulatory blood pressure monitoring; ACC: The American College of Cardiology; BMI: Body mass index; BP: Blood pressure; CKD: Chronic kidney disease: CKD-EPl: Chronic Kidney Disease Epidemiology Collaboration; CVD: Cardiovascular disease; DBP: Diastolic BP; eGFR: Estimated glomerular filtration rate; ESC: European Society of Cardiology; ESH: European Society of Hypertension; HTN: Hypertension; JNC 8: The Eighth Joint National Committee; KDIGO: The Kidney Disease Improving Global Outcome; SBP: Systolic BP; SD: Standard deviation

\section{Acknowledgements}

This study is a part of the requirements for MD degree, the Hebrew University of Jerusalem, Faculty of Medicine (E-G).

\section{Authors' contributions}

Conception and design: ME, IZB-D, E-G. Analysis and interpretation of data: EG, IZB-D. Drafting the article: EG, IZB-D. Revising the article: ME, KT. Providing intellectual content of critical importance to the work described: DR. Pa tient recruitment and final approval of the version to be published: $E G, K T$, $I M-Y L, O G, I S, R A, A B, D R, M A, I Z B-D$, and ME. All authors read and approved the final manuscript.

\section{Funding}

None

\section{Availability of data and materials}

Datasets supporting the conclusions of this article are in part included within the article and its additional files.

The complete datasets generated and/or analyzed during the current study are available from the corresponding author on reasonable request.

\section{Ethics approval and consent to participate}

The Helsinki Committee of the Hadassah Medical Organization approved the protocol for this study.

All volunteers provided written informed consent prior to participation.

\section{Consent for publication}

Not applicable.

\section{Competing interests}

The authors declare that they have no competing interests.

Received: 11 January 2019 Accepted: 27 June 2019

Published online: 27 July 2019

\section{References}

1. Kasiske BL, Chakkera HA, Roel J. Explained and unexplained ischemic heart disease risk after renal transplantation. J Am Soc Nephrol. 2000; 11(9):1735-43

2. Ojo AO. Cardiovascular complications after renal transplantation and their prevention. Transplantation. 2006:82(5):603-11.

3. Kasiske BL, Anjum S, Shah R, Skogen J, Kandaswamy C, Danielson B, O'Shaughnessy EA, Dahl DC, Silkensen JR, Sahadevan M, et al. Hypertension after kidney transplantation. Am J Kidney Dis. 2004;43(6):1071-81.

4. Mange KC, Cizman B, Joffe M, Feldman HI. Arterial hypertension and renal allograft survival. JAMA. 2000;283(5):633-8.
5. Mange KC, Feldman HI, Joffe MM, Fa K, Bloom RD. Blood pressure and the survival of renal allografts from living donors. J Am Soc Nephrol. 2004;15(1): 187-93.

6. Opelz G, Wujciak T, Ritz E. Association of chronic kidney graft failure with recipient blood pressure. Collaborative Transplant Study. Kidney Int. 1998; 53(1):217-22.

7. Paoletti E, Gherzi M, Amidone M, Massarino F, Cannella G. Association of arterial hypertension with renal target organ damage in kidney transplant recipients: the predictive role of ambulatory blood pressure monitoring. Transplantation. 2009:87(12):1864-9.

8. Budde K, Waiser J, Fritsche L, Zitzmann J, Schreiber M, Kunz R, Neumayer $\mathrm{HH}$. Hypertension in patients after renal transplantation. Transplant Proc. 1997:29(1-2):209-11.

9. Wadei HM, Textor SC. Hypertension in the kidney transplant recipient. Transplant Rev (Orlando). 2010;24(3):105-20.

10. Weir MR, Burgess ED, Cooper JE, Fenves AZ, Goldsmith D, McKay D, Mehrotra A, Mitsnefes MM, Sica DA, Taler SJ. Assessment and management of hypertension in transplant patients. J Am Soc Nephrol. 2015;26(6):1248-60.

11. Wheeler DC, Becker GJ. Summary of KDIGO quideline. What do we really know about management of blood pressure in patients with chronic kidney disease? Kidney Int 2013:83(3):377-83.

12. Whelton PK, Carey RM, Aronow WS, Casey DE Jr, Collins KJ, Dennison Himmelfarb C, DePalma SM, Gidding S, Jamerson KA, Jones DW, et al. 2017 ACC/AHA/AAPA/ABC/ACPM/AGS/APhA/ASH/ASPC/NMA/PCNA guideline for the prevention, detection, evaluation, and Management of High Blood Pressure in adults: a report of the American College of Cardiology/American Heart Association task force on clinical practice guidelines. J Am Coll Cardiol. 2018:71(19):e127-e248.

13. Taler SJ, Agarwal R, Bakris GL, Flynn JT, Nilsson PM, Rahman M, Sanders PW, Textor SC, Weir MR, Townsend RR. KDOQI US commentary on the 2012 $\mathrm{KDIGO}$ clinical practice guideline for management of blood pressure in CKD. Am J Kidney Dis. 2013;62(2):201-13.

14. Williams B, Mancia G, Spiering W, Agabiti Rosei E, Azizi M, Burnier M, Clement DL, Coca A, de Simone G, Dominiczak A, et al. 2018 ESC/ESH guidelines for the management of arterial hypertension. Eur Heart J. 2018; 39(33):3021-104

15. James PA, Oparil S, Carter BL, Cushman WC, Dennison-Himmelfarb C, Handler J, Lackland DT, LeFevre ML, MacKenzie TD, Ogedegbe O, et al. 2014 evidence-based guideline for the management of high blood pressure in adults: report from the panel members appointed to the eighth joint National Committee (JNC 8). JAMA. 2014;311(5):507-20.

16. Hodgkinson J, Mant J, Martin U, Guo B, Hobbs FD, Deeks JJ, Heneghan C, Roberts N, McManus RJ. Relative effectiveness of clinic and home blood pressure monitoring compared with ambulatory blood pressure monitoring in diagnosis of hypertension: systematic review. BMJ. 2011:342:d3621.

17. Verdecchia P, Clement D, Fagard R, Palatini P, Parati G. Blood pressure monitoring. Task force III: target-organ damage, morbidity and mortality. Blood Press Monit. 1999;4(6):303-17.

18. Ohkubo T, Hozawa A, Nagai K, Kikuya M, Tsuji I, Ito S, Satoh H, Hisamichi S, Imai Y. Prediction of stroke by ambulatory blood pressure monitoring versus screening blood pressure measurements in a general population: the Ohasama study. J Hypertens. 2000;18(7):847-54.

19. Ohkubo T, Kikuya M, Metoki H, Asayama K, Obara T, Hashimoto J, Totsune K, Hoshi H, Satoh H, Imai Y. Prognosis of "masked" hypertension and "whitecoat" hypertension detected by $24-\mathrm{h}$ ambulatory blood pressure monitoring 10-year follow-up from the Ohasama study. J Am Coll Cardiol. 2005;46(3): $508-15$

20. Staessen JA, Thijs L, Fagard R, O'Brien ET, Clement D, de Leeuw PW, Mancia G, Nachev C, Palatini P, Parati G, et al. Predicting cardiovascular risk using conventional vs ambulatory blood pressure in older patients with systolic hypertension. Systolic hypertension in Europe trial investigators. JAMA. 1999; 282(6):539-46.

21. Pickering TG, Shimbo D, Haas D. Ambulatory blood-pressure monitoring. N Engl J Med. 2006;354(22):2368-74.

22. Pickering TG, Hall JE, Appel LJ, Falkner BE, Graves J, Hill MN, Jones DW, Kurtz T, Sheps SG, Roccella EJ. Recommendations for blood pressure measurement in humans and experimental animals: part 1: blood pressure measurement in humans: a statement for professionals from the Subcommittee of Professional and Public Education of the American Heart Association Council on high blood pressure research. Circulation. 2005; 111(5):697-716 
23. Pickering TG, Coats A, Mallion JM, Mancia G, Verdecchia P. Blood pressure monitoring. Task force V: white-coat hypertension. Blood Press Monit. 1999; 4(6):333-41.

24. Pickering TG, Davidson K, Gerin W, Schwartz JE. Masked hypertension. Hypertension. 2002;40(6):795-6.

25. Sheppard JP, Stevens R, Gill P, Martin U, Godwin M, Hanley J, Heneghan C, Hobbs FD, Mant J, McKinstry B, et al. Predicting out-of-office blood pressure in the clinic (PROOF-BP): derivation and validation of a tool to improve the accuracy of blood pressure measurement in clinical practice. Hypertension. 2016:67(5):941-50.

26. David VG, Yadav B, Jeyaseelan L, Deborah MN, Jacob S, Alexander S, Varughese $S$, John GT. Prospective blood pressure measurement in renal transplant recipients. Indian J Nephrol. 2014;24(3):154-60.

27. Fernandez Fresnedo G, Franco Esteve A, Gomez Huertas E, Cabello Chaves V, Diz Gomez JM, Osorio Moratalla JM, Gallego Samper R, Gallego Valcarcel E, Campistol Plana JM, Marin Iranzo R, et al. Ambulatory blood pressure monitoring in kidney transplant patients: RETENAL study. Transplant Proc. 2012:44(9):2601-2.

28. Wen KC, Gourishankar S. Evaluating the utility of ambulatory blood pressure monitoring in kidney transplant recipients. Clin Transpl. 2012;26(5):E465-70.

29. Kendirlinan Demirkol O, Oruc M, Ikitimur B, Ozcan S, Gulcicek S, Soylu H, Trabulus S, Altiparmak MR, Seyahi N. Ambulatory blood pressure monitoring and echocardiographic findings in renal transplant recipients. J Clin Hypertens (Greenwich). 2016;18(8):766-71.

30. Ahmed J, Ozorio V, Farrant M, Van Der Merwe W. Ambulatory vs office blood pressure monitoring in renal transplant recipients. J Clin Hypertens (Greenwich). 2015;17(1):46-50.

31. Haydar AA, Covic A, Jayawardene S, Agharazii M, Smith E, Gordon I, O'Sullivan H, Goldsmith DJ. Insights from ambulatory blood pressure monitoring: diagnosis of hypertension and diurnal blood pressure in renal transplant recipients. Transplantation. 2004;77(6):849-53.

32. Kayrak M, Gul EE, Kaya C, Solak Y, Turkmen K, Yazici R, Guney I, Altintepe L, Turk S, Ozdemir K. Masked hypertension in renal transplant recipients. Blood Press. 2014;23(1):47-53.

33. Cuspidi C, Macca G, Sampieri L, Fusi V, Severgnini B, Michev I, Salerno M, Magrini F, Zanchetti A. Target organ damage and non-dipping pattern defined by two sessions of ambulatory blood pressure monitoring in recently diagnosed essential hypertensive patients. J Hypertens. 2001;19(9): 1539-45.

34. Wadei HM, Amer H, Taler SJ, Cosio FG, Griffin MD, Grande JP, Larson TS, Schwab TR, Stegall MD, Textor SC. Diurnal blood pressure changes one year after kidney transplantation: relationship to allograft function, histology, and resistive index. J Am Soc Nephrol. 2007;18(5):1607-15.

35. Halimi JM, Persu A, Sarafidis PA, Burnier M, Abramowicz D, Sautenet B, Oberbauer R, Mallamaci F, London G, Rossignol P, et al. Optimizing hypertension management in renal transplantation: a call to action. Nephrol Dial Transplant. 2017:32(12):1959-62.

36. Bursztyn M, Ben-Dov IZ. Sex differences in salt-sensitivity risk approximated from ambulatory blood pressure monitoring and mortality. J Hypertens. 2013;31(5):900-5

37. Piepoli MF, Hoes AW, Agewall S, Albus C, Brotons C, Catapano AL, Cooney MT, Corra U, Cosyns B, Deaton C, et al. 2016 European guidelines on cardiovascular disease prevention in clinical practice: the sixth joint task force of the European Society of Cardiology and Other Societies on cardiovascular disease prevention in clinical practice (constituted by representatives of 10 societies and by invited experts) developed with the special contribution of the European Association for Cardiovascular Prevention \& rehabilitation (EACPR). Eur Heart J. 2016:37(29):2315-81.

38. Andalib A, Akhtari S, Rigal R, Curnew G, Leclerc JM, Vaillancourt M, Tardif JC. Determinants of masked hypertension in hypertensive patients treated in a primary care setting. Intern Med J. 2012;42(3):260-6.

39. Ben-Dov IZ, Ben-Arie L, Mekler J, Bursztyn M. In clinical practice, masked hypertension is as common as isolated clinic hypertension: predominance of younger men. Am J Hypertens. 2005:18(5 Pt 1):589-93.

40. Campistol JM, Romero R, Paul J, Gutierrez-Dalmau A. Epidemiology of arterial hypertension in renal transplant patients: changes over the last decade. Nephrol Dial Transplant. 2004;19(Suppl 3):iii62-6.

41. Margreiter R, European tacrolimus vs Ciclosporin microemulsion renal transplantation study G. Efficacy and safety of tacrolimus compared with ciclosporin microemulsion in renal transplantation: a randomised multicentre study. Lancet. 2002;359(9308):741-6.
42. Mallamaci F, Tripepi R, Leonardis D, Mafrica A, Versace MC, Provenzano F, Tripepi G, Zoccali C. Nocturnal hypertension and altered night-day BP profile and atherosclerosis in renal transplant patients. Transplantation. 2016; 100(10):2211-8.

43. Mallamaci F, D'Arrigo G, Tripepi R, Leonardis D, Porto G, Testa A, Abd ElHafeez S, Mafrica A, Versace MC, Provenzano PF, et al. Office, standardized and $24-h$ ambulatory blood pressure and renal function loss in renal transplant patients. J Hypertens. 2018;36(1):119-25.

44. Drawz PE, Alper AB, Anderson AH, Brecklin CS, Charleston J, Chen J, Deo R, Fischer MJ, He J, Hsu CY, et al. Masked hypertension and elevated nighttime blood pressure in CKD: prevalence and association with target organ damage. Clin J Am Soc Nephrol. 2016;11(4):642-52.

45. limuro S, Imai E, Watanabe T, Nitta K, Akizawa T, Matsuo S, Makino H, Ohashi Y, Hishida A, Chronic kidney disease Japan cohort study G. Clinical correlates of ambulatory BP monitoring among patients with CKD. Clin J Am Soc Nephrol. 2013;8(5):721-30.

46. Covic A, Goldsmith DJ, Gusbeth-Tatomir P, Seica A, Jayawardene S, Agharazii M, Afzali B. What added value does ambulatory blood pressure monitoring brings to the management of post renal transplantation hypertension? Rev Med Chir Soc Med Nat lasi. 2003;107(1):89-97.

47. Taler SJ, Textor SC, Canzanello VJ, Wilson DJ, Wiesner RH, Krom RA. Loss of nocturnal blood pressure fall after liver transplantation during immunosuppressive therapy. Am J Hypertens. 1995;8(6):598-605.

48. Reeves RA, Shapiro AP, Thompson ME, Johnsen AM. Loss of nocturnal decline in blood pressure after cardiac transplantation. Circulation. 1986; 73(3):401-8.

49. Marketou M, Patrianakos A, Parthenakis F, Zacharis E, Arfanakis D, Kochiadakis G, Chlouverakis G, Vardas P. Systemic blood pressure profile in hypertensive patients with low hemoglobin concentrations. Int J Cardiol. 2010;142(1):95-6.

50. Ben-Dov IZ, Kark JD, Ben-Ishay D, Mekler J, Ben-Arie L, Bursztyn M. Blunted heart rate dip during sleep and all-cause mortality. Arch Intern Med. 2007; 167(19):2116-21.

51. Hoorn EJ, Walsh SB, McCormick JA, Furstenberg A, Yang CL, Roeschel T, Paliege A, Howie AJ, Conley J, Bachmann S, et al. The calcineurin inhibitor tacrolimus activates the renal sodium chloride cotransporter to cause hypertension. Nat Med. 2011;17(10):1304-9.

52. Siegel WC, Blumenthal JA, Divine GW. Physiological, psychological, and behavioral factors and white coat hypertension. Hypertension. 1990;16(2):140-6.

\section{Publisher's Note}

Springer Nature remains neutral with regard to jurisdictional claims in published maps and institutional affiliations.

Ready to submit your research? Choose BMC and benefit from

- fast, convenient online submission

- thorough peer review by experienced researchers in your field

- rapid publication on acceptance

- support for research data, including large and complex data types

- gold Open Access which fosters wider collaboration and increased citations

- maximum visibility for your research: over $100 \mathrm{M}$ website views per year

At $\mathrm{BMC}$, research is always in progress.

Learn more biomedcentral.com/submission 